
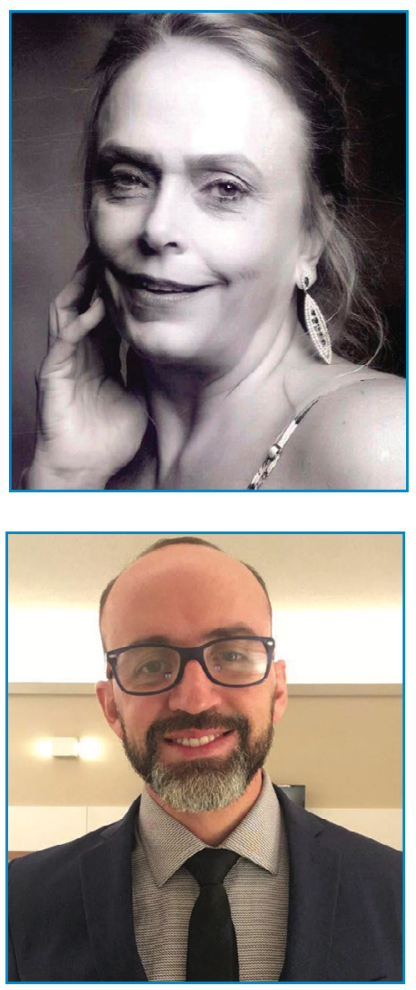

\section{UM CONSENSO BRASILEIRO PARA OS CUIDADOS ÀS PESSOAS ADULTAS COM ESTOMIAS DE ELIMINAÇÃO}

\section{A BRAZILIAN CONSENSUS FOR THE CARE OF ADULTS WITH ELIMINATION OSTOMIES \\ UN CONSENSO BRASILEÑO PARA EL CUIDADOS DE ADULTOS CON OSTOMÍAS DE ELIMINACIÓN}

\section{Maria Angela Boccara de Paula ${ }^{1}$, ] Juliano Teixeira Moraes ${ }^{2, *}$ (iD}

A estomaterapia brasileira, em seus 30 de história, é celebrada com grande entusiasmo. Apesar da pandemia do coronavírus (SARS-COV-2) que assola o mundo, 2020 possibilitou a concretização deste sonho, que foi a construção e validação do primeiro Consenso Brasileiro para o Cuidado de Pessoas Adultas com Estomias de Elimanação. Um consenso é a concordância ou uniformidade de opiniões, pensamentos, sentimentos, crenças etc. da maioria ou da totalidade de membros de uma coletividade ${ }^{1}$.

Assim, esse consenso traz a concordância de opiniões de especialistas, e foi desenvolvido de maneira totalmente on-line e sistematizada, já que o momento não permitiu realizar algumas etapas presencialmente.

O objetivo é apresentar recomendações baseadas em evidência científica, norteando profissionais da saúde e pessoas com estomias para as melhores práticas definidas por critérios, padrões e indicadores da qualidade do cuidado.

Esse documento foi elaborado a partir da iniciativa dos membros da Diretoria da Associação Brasileira de Estomaterapia: estomias, feridas e incontinências (gestão 2018-2020) e contou com o apoio da empresa Coloplast, que viabilizou a revisão das evidências científicas ${ }^{2}$ e reunião dos juízes. Ressalta-se que foi declarada a ausência de conflitos de interesses e não houve nenhum tipo de influência da indústria na elaboração desse consenso.

A produção deste documento contou com um grupo de enfermeiros estomaterapeutas reconhecidos pelo trabalho na assistência, ensino e/ou pesquisa. Ao todo, participaram desse trabalho 13 profissionais: 2 coordenaram o processo, 10 foram juízes avaliadores e 1 realizou a revisão técnica final.

Sua construção obedeceu a critérios rígidos e todo o processo foi desenvolvido em quatro fases:
a. Revisão sistemática da literatura
b. Construção das declarações de consenso
c. Validação das declarações de consenso ${ }^{3}$
d. Revisão técnica

1. Universidade de Taubaté - Departamento de Enfermagem e Nutrição e Programa de Mestrado em Desenvolvimento Humano - Taubaté (SP), Brasil.

2. Universidade Federal de São João del-Rei - Divinópolis (MG), Brasil.

*Autor correspondente: julianotmoraes@ufsj.edu.br

Como citar: Paula MAB, Moraes JT. Um consenso brasileiro para os cuidados às pessoas adultas com estomias de eliminação. ESTIMA, Braz. J. Enterostomal Ther., 2020, 19: e0221. https://doi.org/10.30886/estima.v19.1012_PT 
Inicialmente, foi realizada a revisão sistemática da literatura subsidiada pela elaboração das perguntas de pesquisa que nortearam as buscas. De posse dessas informações, foram construídas as declarações de consenso que, posteriormente, foram apreciadas e validadas pelos juízes. Todas as declarações foram consensuadas com 100\% de concordância. Após essa etapa, foi submetido à revisão técnica realizada por uma profissional com experiência no ensino, assistência e pesquisa na área de estomias e com reconhecimento científico internacional. Foram realizadas adequações em algumas terminologias, ajustamento linguístico da declaração, ajustamento de nomenclaturas para adaptação à linguagem, uma vez que o maior número de publicações utilizadas na elaboração desse consenso era de língua estrangeira, e reorganização de algumas declarações que, por ventura, estavam repetidas ou alocadas em categorias diferentes.

Foi possível validar 200 declarações de consenso para o cuidado às pessoas adultas com estomias de eliminação. Além das declarações para o cuidado, também foi consensuado pelos organizadores e grupo de juízes o detalhamento de 3 procedimentos fundamentais para a assistência: demarcação da estomia ( 25 declarações), controle intestinal (20 declarações) e uso do oclusor (12 declarações).

O processo foi intenso e longo. A colaboração e a expertise de cada profissional colaborador contribuiu sobre maneira para esse resultado.

O consenso final servirá de norte para que profissionais e instituições de saúde elaborem e desenvolvam protocolos, programas e serviços especializados baseados em evidência. Também auxiliará a compreender a realidade que compõe o universo das pessoas com estomia no Brasil, de forma a orientar a tomada de decisões mais assertivas e, portanto, contribuir na melhoria da assistência.

Espera-se, ainda, que esse documento sirva para balizar as políticas públicas de atenção à saúde das pessoas com estomias. Dessa maneira, contribuir para a implementação de uma assistência integral que considere as particularidades desse cuidado que muitas vezes se encontra escondido ou invisível aos olhos da comunidade e dos responsáveis pela saúde no país.

Essa iniciativa é muito importante, primeiramente, porque a estomaterapia teve sua origem no cuidado de pessoas com estomias e essa é uma das principais áreas de atuação do enfermeiro estomaterapeuta. Também é necessário considerar o ineditismo desse trabalho no Brasil e as possibilidades que traz para profissionais e instituições de saúde e, consequentemente, para as pessoas com estomias.

Espera-se que iniciativas como essa possam ser motivadas e replicadas em outras áreas da especialidade, considerando todo rigor metodológico e a ética com que esse documento foi elaborado.

Portanto, utilizem esse material com o desejo de assistir com qualidade e mostrar para o mundo a importância e a diferença que o profissional preparado é capaz de fazer.

\section{REFERENCIAS}

1. Ferreira ABH. Dicionário Aurélio da Língua Portuguesa. 5ed. Curitiba: Positivo, 2014.

2. E1 Dib, R. Guia prático de medicina baseada em evidências. 1. ed. São Paulo: Cultura Acadêmica, 2014. (Coleção PROEX DigitalUNESP). Disponível em: http://hdl.handle.net/11449/126244

3. Ludlow, J. (1975). Delphi inquiries and knowledge utilization. In H. A. Linstone, \& M. Turoff (Eds.). The Delphi method: Techniques and applications (pp. 102-123). Reading, MA: Addison-Wesley Publishing Company. 